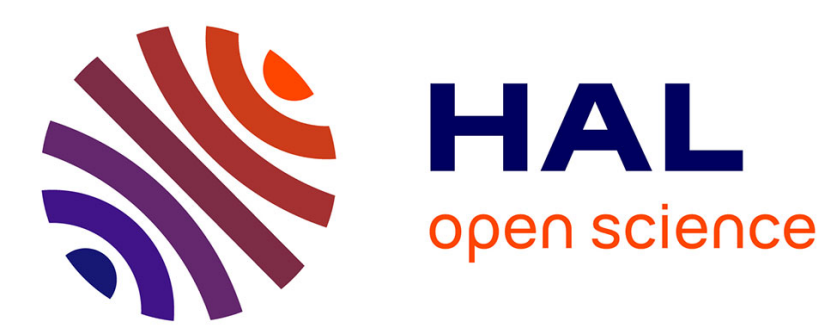

\title{
Martensitic Transformation Under Loading and the Mechanical Properties of Iron Alloys
}

\author{
E. Estrin
}

\section{To cite this version:}

E. Estrin. Martensitic Transformation Under Loading and the Mechanical Properties of Iron Alloys. Journal de Physique IV Proceedings, 1996, 06 (C1), pp.C1-429-C1-434. 10.1051/jp4:1996141 . jpa00254173

\section{HAL Id: jpa-00254173 https://hal.science/jpa-00254173}

Submitted on 1 Jan 1996

HAL is a multi-disciplinary open access archive for the deposit and dissemination of scientific research documents, whether they are published or not. The documents may come from teaching and research institutions in France or abroad, or from public or private research centers.
L'archive ouverte pluridisciplinaire HAL, est destinée au dépôt et à la diffusion de documents scientifiques de niveau recherche, publiés ou non, émanant des établissements d'enseignement et de recherche français ou étrangers, des laboratoires publics ou privés. 


\title{
Martensitic Transformation Under Loading and the Mechanical Properties of Iron Alloys
}

\author{
E.I. Estrin
}

Institute of Physical Metallurgy, 2 Baumanskaya st., 9/23, 107005 Moscow, Russia

\begin{abstract}
The martensitic transformation (MT) under tensile deformation at $77 \mathrm{~K}$ in a serjes of Fe$\mathrm{Ni}-\mathrm{Mn}$ alloys was studied. The amount of martensite formed during the tensile test depends on the applied stress and on the Mn content which determines the martensitic point and the MT start stress. Elongation of the tensile tested samples has a maximum value in the alloys containing the $50 \%$ amount of martensite formed during the tensile test. Parameters which determine the intensity of the MT and plasticity of the samples under loading are discussed.
\end{abstract}

\section{INTRODUCTION}

Martensitic transformations (MT) are accompanied by the deformation of shape of the regions undergoing the transformation [1-3], that defines the existence of interaction between the MT and external forces. This interaction manifests itself in the shift of the temperature range of MT under the influence of external stresses, which is described by the Clapeyron equation [4-6], in the selection of orientation variants of martensite crystals and others. From the other side, transformation under loading leads to the specific features of deformation behavior of the materials undergoing the MT. In the materials where the deformation of shape at MT is small and could be elastically accommodated, the hysteresis of transformation is small and several effects, such as superplasticity and restoration of the initial shape at the reversal transformation (shape memory effect) are observed at loading. When the deformation of shape at MT is large and can't be elastically accommodated, transformation is accompanied by plastic relaxation, hysteresis of transformation is large and the other specific phenomenon, enhanced plasticity, comnected with the MT under loading (TRIP-effect), is observed [7-8]. The majority of investigations which are being carried out now are directed to the study of the materials of the first type. Materials with the significant deformation of shape at MT (typical representatives are the iron based alloys with f.c.c. b.c.c. transformation) are studied less intensively. As a result a number of problems connected with the MT in these alloys at loading and the anomalies of their mechanical properties are still not solved. Thus, factors defining the development of the MT under loading in these materials, conditions of the maximum exhibition of the TRIP-effect, possibilities of the control of this effect are unclear.

Experimental study of these problems is the aim of the present work.

\section{EXPERIMENTAL}

Study was carried out at the series of Fe-Ni-Mn alloys with the composition presented in Table 1. Very slow isothermal transformation was observed in all of the studied alloys in the 
low temperature region. After cooling in liquid nitrogen austenite phase of the alloys completely retains (exept the A and B alloys where a small amount of martensite, $15 \%$ and $3 \%$ correspondingly, is formed).

Cylindrical samples of $3 \mathrm{~mm}$ diameter of working part, annealed for $10 \mathrm{~h}$ at $1150^{\circ} \mathrm{C}$, were cooled to $77 \mathrm{~K}$ and tensile tested at this temperature using the testing device $1 \mathrm{M}-12$ provided with tensometric transmitter for detection of stress. During stretch at $77 \mathrm{~K}$ the stress $\sigma$, deformation $\varepsilon$ and amount of formed martensite $\alpha$ were measured. Amount of martensite was measured using the inductive magnetometer.

Table 1. Chemical composition of the alloys (weight \%).

\begin{tabular}{|c|c|c|c|c|}
\hline Alloy & $\mathbf{C}$ & $\mathrm{Ni}$ & $\mathrm{Mn}$ & $\mathrm{Fe}$ \\
\hline $\mathrm{A}$ & 0.03 & 22.8 & 3.34 & the rest \\
\hline B & 0.03 & 22.8 & 3.70 & - \\
\hline C & 0.03 & 22.8 & 3.98 & - \\
\hline D & 0.02 & 22.8 & 4.00 & - \\
\hline E & 0.03 & 22.65 & 4.63 & - \\
\hline F & 0.025 & 22.9 & 4.86 & - \\
\hline G & 0.03 & 22.9 & 4.91 & - \\
\hline H & 0.01 & 22.7 & 5.05 & - \\
\hline I & 0.01 & 22.8 & 6.05 & - \\
\hline
\end{tabular}

\section{RESULTS}

Tensile test curves at $77 \mathrm{~K}$ for the alloys with the different $\mathrm{Mn}$ content are presented in Fig. 1. As the Mn content increases (that corresponds to decrease of equilibrium temperature $T_{0}$ of austenite and martensite and to decrease of martensite point $M_{s}$ ) the slope of the curves $\sigma-\varepsilon$ decreases, the ultimate tensile strength $\sigma_{\mathfrak{u}}$ remains approximately constant. Exception is the I alloy with the maximum content of $\mathrm{Mn}$, which has the lower ultimate tensile strength. Elongation $\delta$ increases with the increase of the Mn content except the I alloy. In the $\mathrm{I}$ alloy $\delta$ is less than that in the E, F, G and $\mathrm{H}$ alloys.

The dependence of the amount of martensite $\alpha$, formed during the tensile test, on deformation $\varepsilon$ is presented in Fig.2. As the content of Mn increases, the intensity of the MT during the deformation decreases, slope of the $\alpha-\varepsilon$ curves decreases. More than $90 \%$ of martensite is formed at deformation in the A, B and C alloys, about $3 \%$ only - in the I alloy.

The external thermodynamic parameter conjugated with the internal parameter of system, the deformation of shape at transformation, is the stress $\sigma$ [4-6,9], and the $\alpha-\varepsilon$ curves were recalculated to $\alpha-\sigma$ curves using the experimental $\sigma-\varepsilon$ curves (Fig.3). In the $\alpha-\sigma$ coordinates the transformation curves represent themselves a set of nearly parallel curves, shifted against each other (Fig.3). As the Mn content increases, the curves shift to the bigger $\sigma$ and lower $\alpha$. It may be concluded from Fig. 3 that the progress of the MT at deformation is defined by the increase of thermodynamic driving force at the expense of the work of the external forces on deformation of shape [4-6,9].

Transformation at loading starts at a critical value of the external stress $\sigma_{\mathrm{Ms}}$. The value of $\sigma_{\mathrm{Ms}}$ varies according to equation analogous to the Clapeyron equation

$$
\mathrm{dM}_{\mathrm{S}} / \mathrm{d} \sigma=\mathrm{dT}_{0} / \mathrm{d} \sigma=\varepsilon_{0} \mathrm{~V} / \Delta \mathrm{S}=\varepsilon_{0} \mathrm{VT}_{0} / \Delta \mathrm{H},
$$


(where $\varepsilon_{0}$ is the deformation of shape, $\mathrm{V}$ is mole volume, $\Delta \mathrm{S}$ and $\Delta \mathrm{H}$ - change of entropy and enthalpy at MT) by the distance between the martensite point and the temperature of test. The lower is $M_{s}$, the bigger is the value of $\sigma_{M s}$.

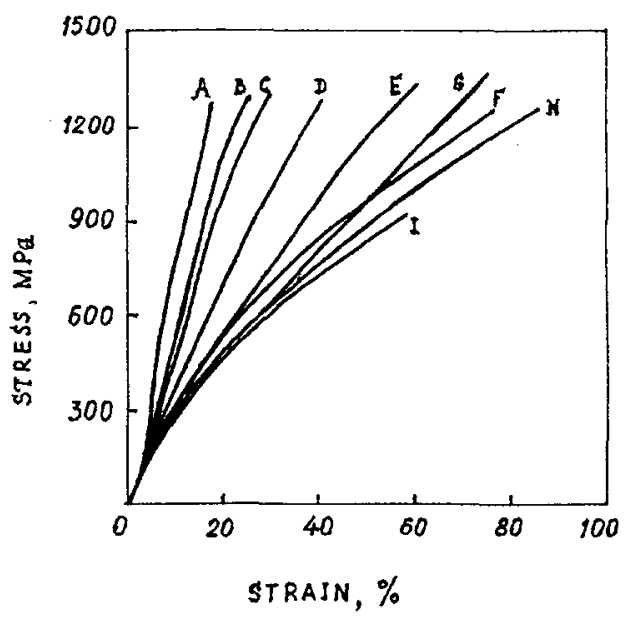

Fig. 1. Tensile test curves of the Fe-Ni-Mn alloys at $77 \mathrm{~K}$.

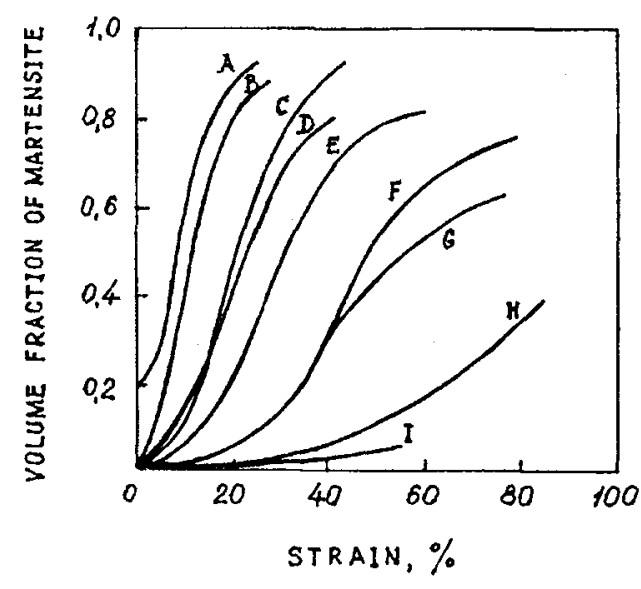

Fig.2. Dependence of the amount of martensite $\alpha$ formed in the $\mathrm{Fe}-\mathrm{Ni}-\mathrm{Mn}$ alloys at stretching at $77 \mathrm{~K}$ on the deformation $\varepsilon$.

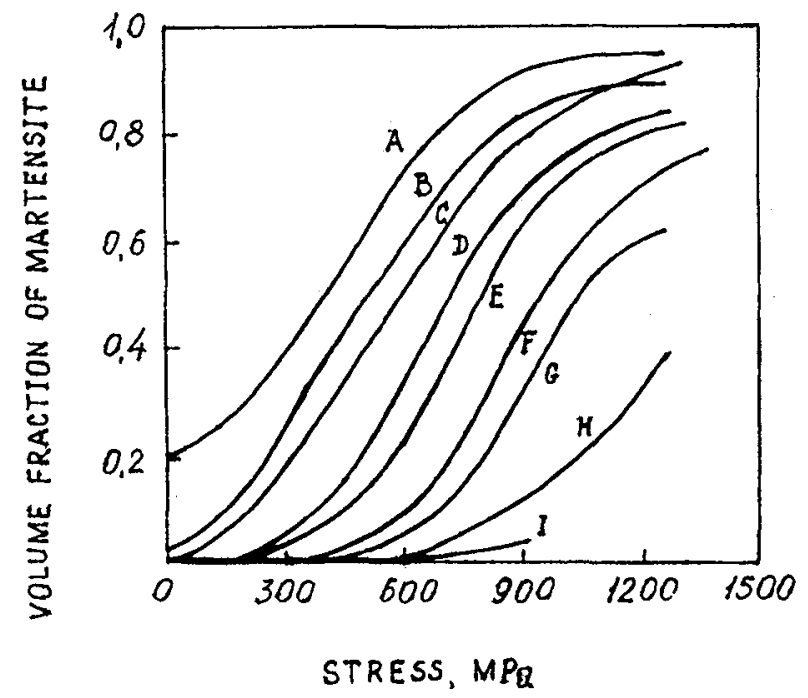

Fig.3. Dependence of the amount of martensite $\alpha$ formed in the Fe-Ni-Mn alloys at tensile test at $77 \mathrm{~K}$ on stress $\sigma$.

Dependence of $\sigma_{\mathrm{Ms}}$ on the $\mathrm{Mn}$ content is presented in Fig.4. The value of $\sigma_{\mathrm{Ms}}$ was defined from the data of Fig. 3 by extrapolation of the linear part of the $\alpha-\sigma$ curve to zero amount of martensite. Dependencies of the ultimate tensile strength $\sigma_{\mathfrak{u}}$, obtained from Figs. 1 and 2 , and the value of stress $\sigma_{\mathrm{M} 0.5}$ corresponding to the formation of $50 \%$ of martensite, on 
the $\mathrm{Mn}$ content are also presented in Fig.4. According to the above results, $\sigma_{\mathrm{Ms}}$ and $\sigma_{\mathrm{M} 0.5}$ increase with the increase of $\mathrm{Mn}$ content (or the $\mathrm{M}_{\mathrm{S}}$ decrease).

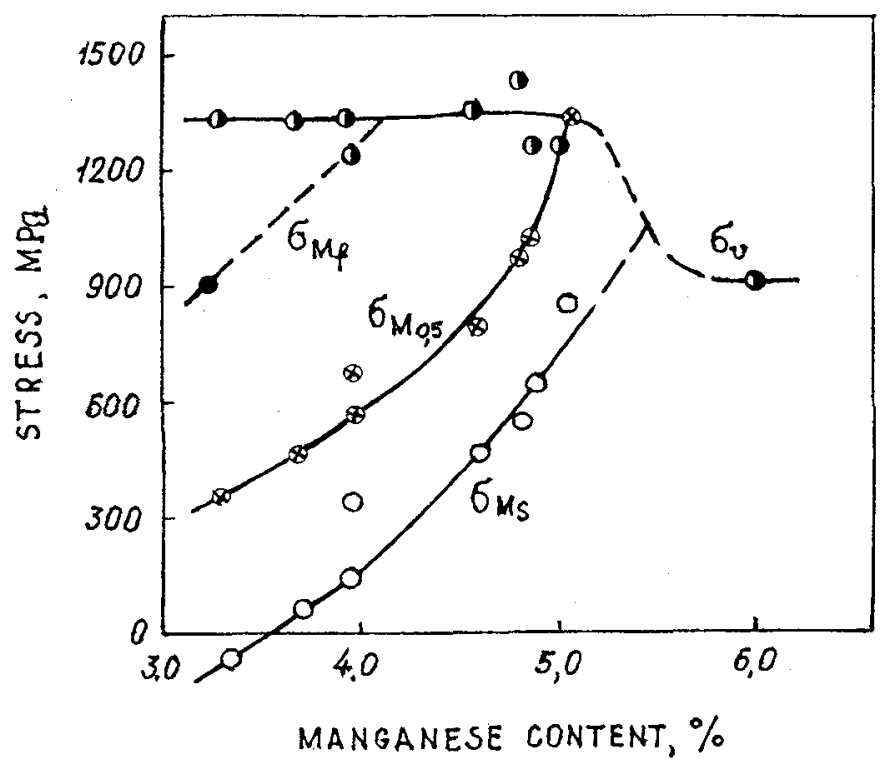

Fig.4. Dependence of the ultimate tensile strength $\sigma_{\mathrm{u}}$, start stress of MT $\sigma_{\mathrm{Ms}}$, stress corresponding to the formation of $50 \%$ of martensite $\sigma_{\mathrm{M} 0.5}$ and stress of the finish of the MT $\sigma_{\mathrm{Mf}}$, versus the manganese content of the alloys.

Dependence of the amount of martensite $\alpha$ which is formed during the tensile test and elongation $\delta$ on the $\mathrm{Mn}$ content is presented in Fig.5. Amount of martensite increases with decrease of $\mathrm{Mn}$ content according to a curve which has the same shape as the martensite curve. Elongation increases with decrease of $\mathrm{Mn}$ content from the value characteristic for elongation of nearly fully austenite $(\delta \sim 50 \%)$, passes the maximum and then decreases continuously, approaching the value which is characteristic for martensite $(\delta \sim 5 \%)$. Maximum value of $\delta$ is observed in the alloys where about $50 \%$ of martensite is formed during the tensile test. This is displayed obviously in Fig.6, where the dependence of elongation on the amount of martensite is presented.

\section{DISCUSSION}

The results of experiments allow to make some conclusions.

Firstly, progress of the MT at stretch in the studied alloys, where the MT is purely isothermal, shows that the isothermal character of transformation in these alloys is connected with insufficient thermodynamic driving force for athermal MT. If the thermodynamic driving force increases at the expense of the external stress, the transformation gains the features of usual athermal MT. This effect is analogous to that established by the investigations of action of the external magnetic field on MT [10].

Secondly, the experimental results show that the maximum plasticity (maximum TRIP effect) is observed in the case when $50 \%$ of martensite is formed during the tensile test. This effect, that have been pointed out in [11], could be explained by the action of two factors. From one side, TRIP effect is connected with the formation of martensite under loading 
(which probably leads to relaxation of stress peaks and prevents the process of destruction) and must increase as the amount of martensite, formed at loading, increases. From the other side, formation of martensite leads to exhaustion of the plastic austenite phase, in which the deformation takes place. The first effect is proportional to the amount of martensite $\alpha$, the second - to the amount of austenite $(1-\alpha)$. So the elongation is proportional to $\alpha(1-\alpha)$ and has a maximum at $\alpha=1 / 2$, i.e. at $50 \%$ of martensite.

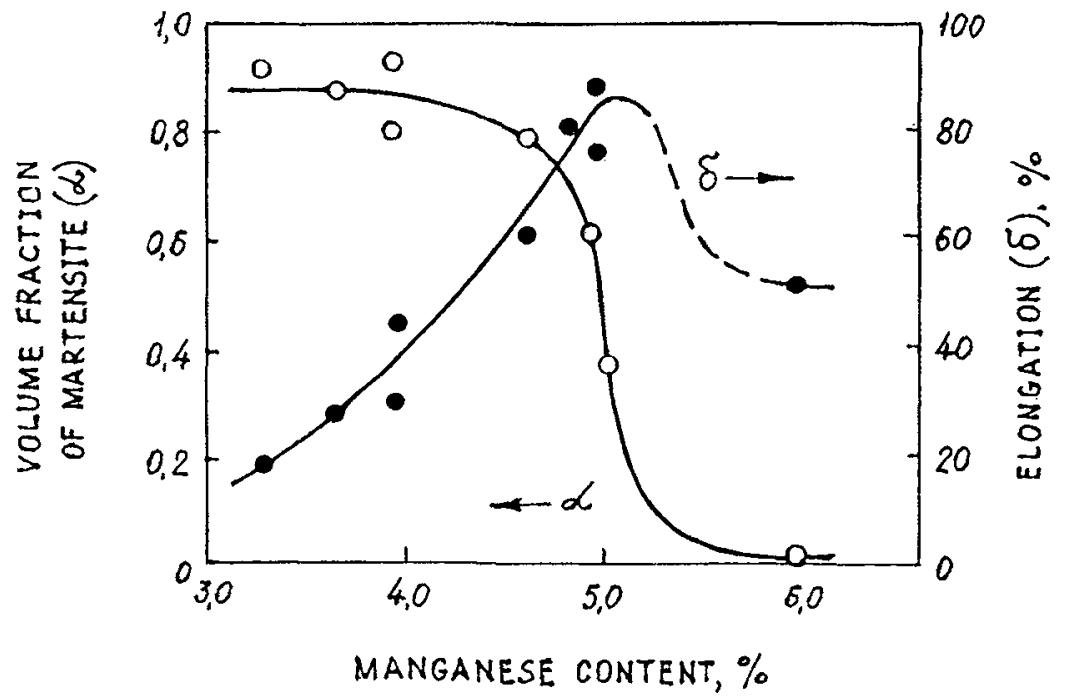

Fig.5. Dependence of the amount of martensite $\alpha$ formed at tensile test at $77 \mathrm{~K}$ and elongation $\delta$ on manganese content.

As follows from Fig.7, which is plotted using the data from Fig.3, $\sigma_{\mathrm{u}}$ reaches the maximum possible value for these alloys at $\alpha \approx 0.5$. So the optimal combination of properties, maximum strength and maximum plasticity, is achieved in the alloy where $50 \%$ of martensite is formed during the tensile test.

Plasticity of alloys, where the amount of martensite at deformation is more or less than $50 \%$, can be increased by the treatment leading to stabilization of austenite, lowering of martensite point - in the first case (e.g. by preliminary plastic deformation of austenite above $\mathrm{M}_{\mathrm{s}}$ ) or its rising - in the second case (e.g. by means of aging leading to the lowering of concentration of solid solution).

\section{CONCLUSIONS}

MT at loading is conditioned by the increase of thermodynamic driving force at loading that leads to the increase of temperature of thermodynamic equilibrium of austenite and martensite phases and corresponding increase of martensite point.

Maximum plasticity at deformation is observed when about $50 \%$ of martensite is formed during the tensile test. This effect is conditioned by two factors: increase of the amount of martensite leading to the increase of plasticity and exhaustion of plastic austenite.

Alloys where about $50 \%$ of martensite is formed at loading possess the optimal combination of high plasticity and strength, that is nearly the same as in the purely martensite alloys. 


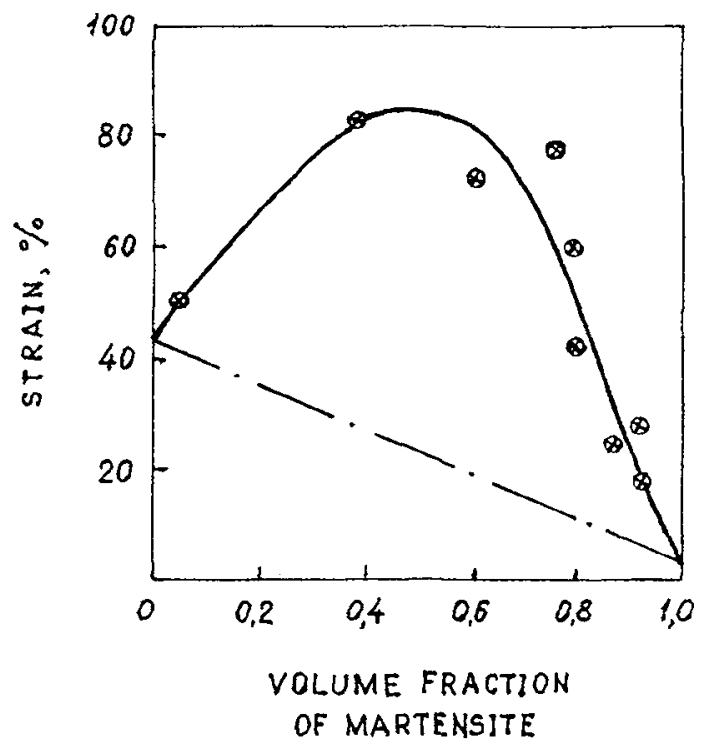

Fig.6. Correlation between elongation $\delta$ at the tensile test of $\mathrm{Fe}-\mathrm{Ni}-\mathrm{Mn}$ alloys at $77 \mathrm{~K}$ and the amount of martensite $\alpha$ formed during the test.

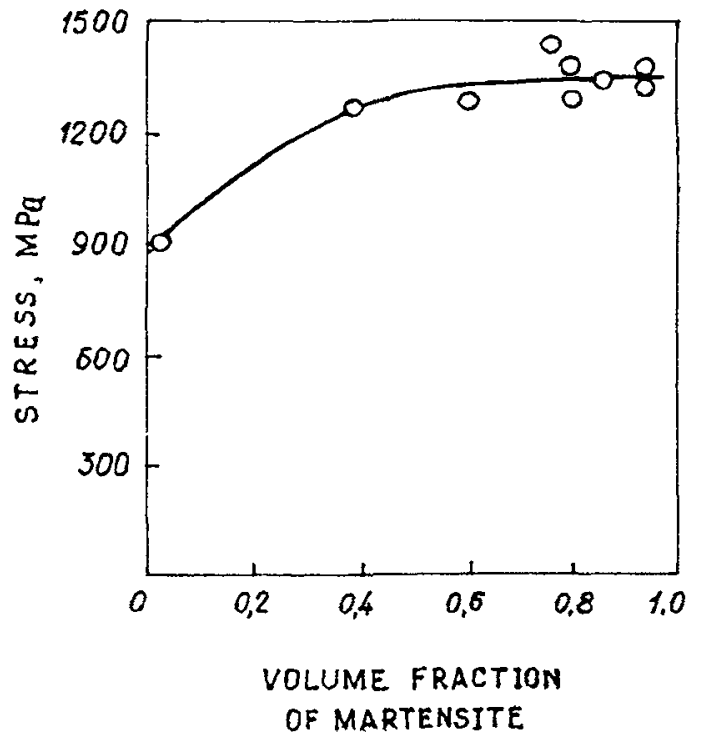

Fig.7. Ultimate tensile strength $\sigma_{u}$ of Fe$\mathrm{Ni}-\mathrm{Mn}$ alloys, tested at $77 \mathrm{~K}$, as a function of the amount of martensite $\alpha$ formed during the test.

\section{References}

[1] Kurdyumov G.V., Zhurnal Tekhnicheskoy Fiziki 18 (1948) 999-1025.

[2] Christian J.W., The Theory of Transformation in Metals and Alloys (Pergamon Press, Oxford 1965) pp.802-931.

[3] Roitburd A.L., Solid State Phys. 33 (1978) 317-390.

[4] Patel I.R. and Cohen M., Acta Met. 1 (1953) 531-538.

[5] Burkart M.W. and Read T.A., J. Metals 5 (1953) 1516.

[6] Wollants P., Roots J.R. and Otsuka K., Z. Metallk., 82 (1991) 182.

[7] De Jong M. and Rathenau G.M., Acta Met. 7 (1959) 246.

[8] Greenwood G.W. and Johnson R.H., Proc. Roy. Soc., A283 (1965) 403.

[9] Serebryakov V.G. and Estrin E.I., Fizika metallov i metallovedenie 70 (1991) 145-148.

[10] Krivoglaz M.A., Sadovskiy V.D., Smirnov L.V. and Fokina E.A., Zakalka stali v magnitnom pole (Nauka, Moscow, 1977) pp.3-119.

[11]. Bressanelli J. and Moskowitz A., ASM Trans. Quart., 59 (1966) 223-239. 